\title{
The Potential of Arabic as a Tourism Language in Malaysia
}

\section{Hashim Bin Mat Zin}

Faculty of Islamic Studies Department of Arabic Studies and Islamic Civilization National University of Malaysia hashimbes@yahoo.com.my

\section{Tengku Ghani Tengku Jusoh}

Faculty of Islamic Studies Department of Arabic Studies and Islamic Civilization

National University of Malaysia tgtj@pkrisc.cc.ukm.my

\section{Zulkarnain Mohamed}

Faculty of Islamic Studies Department of Arabic Studies and Islamic Civilization National University of Malaysia nain@ukm.my

\section{Roslan Abdul Rahman}

Faculty of Islamic Studies Department of Arabic Studies and Islamic Civilization

National University of Malaysia roslana98@gmail.com

\section{Noorsafuan Che Noh}

Faculty of Islamic Studies Department of Arabic Studies and Islamic Civilization National University of Malaysia

Safone2448@gmail.com

\section{Doi:10.5901/jesr.2013.v3n7p490}

\section{Abstract}

Use of Arabic language is seen as to play its role in Malaysian tourism industry. It is common that Arabic is the language of communication for Arab tourists with tourism agents and members of the public such as taxi drivers, traders, security officers and so on. The objective of this study is to evaluate the potential of Arabic language in Malaysian tourism industry. This study used both quantitative and qualitative using questionnaire and interview instruments. As for the quantitave data, the sampling technique involves 10 tourists whereas for the qualitative data an officer from the Islamic Tourism Center was interviewed. It was found in this study that the potential of Arabic language in the tourism industry was most encouraging. The number of the Arab tourists coming to visit is seen to be increasing if related information thas was needed by the tourists can be introduced in Arabic such as in the form of brochurers and signboards as well as television programmes. Besides, Arabic language was expected to be able to create job oppotunities for the local people and subsequently to be able to increase the national economy.

Keywords: potential, tourism, Arabic language, tourism language, types of tourism. 


\section{Introduction}

Language is a medium to spread information. The use of Arabic language in tourism sector seems to play an important role. It was used during communication, advertising, management and to spread information. Arabic language can be considered as a second language for certain population in Malaysia. Any second language learning was eventually to achieve proficiency in using that language practically. Linguist from this group considered second language as a tool, and important tool to help us to achieve many objectives or to get successful in our career (Zulkifley, 2000). Effective communication method was very important in boosting the market value of any tourist guide and individual or those who were involved, as well as interesting advertisement that will increase the number of Arab tourist to Malaysia. Proficiency in using Arabic language will eventually helps in terms of promoting the history, culture and heritage of any tourism spot. It will also contribute to the growth of tourism industry in any nation. Apart from that, a comprehensive and strategic management method as well as effective information delivery will lead to positive impact on increasing the quantity of tourists from the Middle East.

This can be proven with a statistic from the ministry of tourism where there are only 245,302 Arab tourist in the year 2007 but for the year 2008, the number increased to 264,338 . The number continuously increased to more than 248,890 tourists in the year 2009. According to Badaruddin (2008) certain people predict that tourism sectors wills always develop and will last for eternity. Many predict that the number of foreign tourist will keep on increasing.

In order to meet the expectation and the hope of the Malaysian government, this study can become a measure stick to the factors that lead to the increase of tourist from West Asia especially to Malaysia. It is because of the potential and the role of Arabic language itself in tourism industry in Malaysia. It covers the aspects of the usage of Arabic language among tourist guides, personnels at the tourism center's counters, public departments and public universities as well as private universities. This study utilized both the questionnaires and interview method. The related literature review shows that Arabic language play an important role in tourism sectors, creating job opportunities and contribute the national economic growth. As stated by Ahmad Shuib \& Noor Aziz (1989) there are five main benefits from the development of tourism industry that is, contributed to national balance of payments, the development of non industrial area, creating job opportunities, increasing the revenue to the whole economy through impact multipliers and helps social growth.

\section{Statement of Problems}

There were previous studies about the potential of communicational Arabic language as a language of tourism that contribute to tourism sectors and local communities in the aspects of socio economy and culture. Findings by Kurt et al (2012) stated that the improvement in working skills and customer communication will contribute to the increasing number of the tourists. There were so many problems and difficulties in tourism management due to the lack of observation from those involved parties in taking actions to find the solutions.

According to the statistic by the Malaysian Ministry of Tourism, there have been an increasing numbers of Arab tourists to Malaysia from year to year. This matter is due to the 9-11 tragedy that leads more Arab tourists come to Malaysia. The data from the Malaysian ministry of tourism have shown that only 245,302 Arab tourists visited Malaysia in the year 2007. But for the year 2008, the figure changed to 264,338 . For the year 2009 , the figure increased to 284,890 although the data achieved only from January to October 2009 (the ministry stated that the data for November and December 2009 cannot be access due to technical problems). Ahmad Azmi (2009) in his article entitled Marketing Malaysia To The Midddle East Tourist: Towards A Preferred Inter-Regional Destination estimated that as many as 35 million Arab tourists the the Middle East will come to Malaysia by the year 2020.

The presence of these Arab tourists clearly requires preparation and cooperation from all of us and the use of Arabic language must be improved however many from those who have to deal with Arab tourists are not be able to communicate in Arabic. Based on the information from the tourism guide and tourism centers, they were having problems in certain aspects such as having tourist guides that possess high proficiency in Arabic, tourism information in Arabic and last but not least the staff who are good in Arabic. Up until now, there are programmes related to tourism and exploration in public and private universities such as at UiTM, polytechnics and community college. However, the community college still did not put the Arabic modules in their programmes. Based on previous studies, such as by Lazim (2000) stated that the development of other languages such as Arabic was quite isolated and neglected and the Arabic lessons have become static and imbalanced. According to Nik Farhan (2002), students from Universiti Putra Malaysia (UPM) were still weak in Arabic morphology, although they were taking Bachelor Degree in Arabic Literature. Moreover, a study done by 
Nurazan (2004) stated that the students from Sultan Zainal Abidin Islamic College (KUSZA) were having many obstacles affecting their Arabic lesson such as, low input environment, very short class lesson, unstable syllabus, lack of quality materials and so on. These situations contributed to the low level of Arabic proficiency whether from the aspect of speaking, reading and writing. This study will clarify the importance of focusing on Arabic language in tourism sectors in higher learning institutions that offered tourism and exploration related programmes.

Based on the statement of problems above it can be concluded that the number of Arab tourists visiting Malaysia should be improved by making effective planning in the aspect of Arabic language, providing suitable facilities and proper arrangement of related events. Because of that a study to identify the potential of Arabic language in Malaysia' tourism industry should be conducted. This study will explore deeper on the usage of Arabic language in related areas.

\section{Previous Studies}

Past studies have been referred to ensure the validity and the originality of this study. There were many thesis and articles based on the study of Arabic language and its relation in tourism. However specific studies on the potential of Arabic language as a language of tourism have not been conducted so far. The previous studies were focusing on tourism centers, the importance of Arabic language and career prospects among students in higher learning institution and also teaching and learning Arabic for specific purposes.

A study on Malaysia Tourism Center (MTC) as the tourist information center has been conducted by Hazlin (2007) by looking at responses among travelling agencies. That particular study focussed on the role of MTC and the results have suggested a few measures for the improvement and the effectiveness of MTC as a tourist information centre. He have stressed out on the five aspects that need to be emphasized by any tourism centre which are strategic and suitable location, complete and detailed information, effective promotions, physical attraction and events as well as the services/facilities offered.

The next previous study based on a journal entitled The Importance of Arabic Language in Malaysian Tourism Industry: Trend During 1999-2004 by Azman Che Mat, Azman Zakaria and Kamaruzaman Jusoff. Their article was published in the Journal of Canadian Social Science in 2009 and that particular journal discussed on the importance of Arabic language in tourism industry in Malaysia. This journal recorded that since the year 2000, the number of Arab tourists who have visited Malaysia have been increased to 156,000 and each tourist have spent about RM5, 000.00 per trip and it clearly shows the potential and the importance of Arabic language usage in Malaysian tourism sector. Moreover, the use of Arabic language specifically in tourism industry will become a big opportunity for Malaysia in terms of improving the tourism industry and boosting the economic growth.

Meanwhile an article entitled The use of Arabic language in the communication among tourist guides towards promoting Malaysia by Zalika Adam have been published in the year 2009. In this article, she has stressed out the aspect on the use of Arabic language as a medium language in promoting Malaysia among tourists from West Asia. This article explained clearly on the importance of Arabic language among future tourist guide to compete themselves in tourism sectors. They were considered as an agent or as a small ambassador in promoting Malaysia in the eyes of the world. Therefore related knowledge about Malaysia especially the historical facts that will be passed to the tourist guide must be parralled with the target needs thus following the specific guidelines.

Another study conducted by Lazim (2000) and he had already studied and analyzed about the needs of studying Arabic language apart from the need of stdying Arabic language for Islamic related studies. His findings showed that the purpose and the objective of Arabic language programmes in Malaysia only focussed on the need to understand and to apreciate the religion of Islam. Based on his study, he also found out that the purposes and the learning objectives are not parralled to the student's need and the learning and teaching approaches were not suitable with the bacis principal of the formation of syllabus and Arabic language teaching methodology as a second language.

In general, all the previous studies did not really focussed on the potential of Arabic language as a language of tourism as being proposed for this particular study. Therefore this study will emphasize on the potential of Arabic language as a language of tourism in Malaysia.

\section{Purpose of Study}

The main purpose of this study is to study about the potential of Arabic language usage in tourism industry and the related job opportunities especially in Malaysia. 


\section{Objective of Study}

This study has been conducted in order to fulfil the following objectives:

i. To identify the needs on the use of Arabic language in the communication among individual or unit and department that was related to tourism.

ii. To see the relationship between student's job opportunities when they possess good oral communication skills.

iii. To propose the strategies that need to implemented in order to improve the communication skills for the enhancement of the tourism industry.

\section{Research Methodology}

This study will only focussed on the use of Arabic language as an oral communication tools among tourists. The sample for this study consist of 10 Arabic tourist and the selection of the samples were made by purposive sampling, where a group of subject that possess a certain characteristic only then will be selected as respondent. According to Ahmad Sunawari (2009), purposive sampling is a chosen sample based on the desired criteria determined by the researcher in conjunction with the purpose and the objective of the study. For this study, the researchers have determined some of the following criteria against the respondent that later on will become a sample, these includes:

i. 12 years of age and above.

ii. Tourism that can be categorized as sustainable tourism, heritage tourism, environmental tourism, ethnic and cultural tourism and medical tourism. Therefore educational tourism is not listed in the sample of this study.

iii. Stayed in Malaysia for at least three days or more.

In order to achieve the desired information the researchers have used the same type of question only however it was according to the different situations and places.

1. Do you have problems in oral communication when you are at the airport?

2. Do you have problems in oral communication when you are at the hotel (accomodation)?

3. Do you have problems in oral communication when you are dealing with the tourist guide?

4. Do you have problems in oral communication when you are dealing with the taxi driver?

5. Do you have problems in oral communication when you are at the market?

In addition, an officer from the Islamic Tourism Centre (ITC) was interviewed for the sake of this study. ITC was created to improve the Islamic tourism in Malaysia. The interview was a face-to-face interaction between the researcher and the respondent. The interview session was held in order to obtained information from the respondent orally (Chua 2006). The question that was asked in relation to this study is: What are the common problems faced by the Arab tourists when they are in Malaysia?

Due to the limitation of this preliminary study only one officer from ITC and only 10 Arabic tourists have been successfully interviewed.

\section{Location of the Study}

This study has been conducted at the location mostly at the hotels around Kuala Lumpur. The researchers decided to choose the hotels around Kuala Lumpur due to the heavy population of Arab tourists around the particular area.

\section{Findings of Study}

The findings have been categorized into several situations and settings such as at the airports, hotels, dealing with tourist guide and taxi drivers and also at the market:

Airport: The data showed that $70 \%$ of the respondents were having communication problems at the airport. 30\% of the respondents admitted that they were not having any problems in communication at the airport.

Hotel (accommodation): The data analysis indicated that $80 \%$ of the respondents reported that they were having communication problem when they are at the hotels as compared to $20 \%$ of the respondents that did not have communication problem.

Tourist Guide: Based on the findings, it clearly showed that $80 \%$ of the respondents claimed that they were having some sort of communication problems while dealing with the tourist guide and the rest $20 \%$ of the respondents seemed 
not to have any problem while dealing with the tourist guide.

Taxi Driver: $90 \%$ of the respondents stated that they were having communication problem while dealing with taxi drivers and only $10 \%$ of them who did not have any problems dealing with taxi drivers.

Market: The findings showed that $80 \%$ of the respondent were indeed having communication problems while shopping but the rest $20 \%$ of respondents did not having any communication problem while shopping at the market.

The above findings also indicated that the skills in Arabic language are very important and those who were involved in tourism sectors should be able to possess the skills especially the Malaysian citizen so that they can communicate in Arabic better.

Based on the interview with an officer from ITC, he claimed that among the common problems faced by the Arab tourists are:

i. Lack of hotel staff that can communicate in Arabic.

ii. $\quad$ No Arabic channel at the hotel.

iii. Tourist guide with low proficiency in Arabic

iv. Taxi drivers cannot speak Arabic.

v. Tourist police cannot communicate in Arabic

vi. Lack of signboard in Arabic

This study showed that the use of Arabic language is very important especially in a communication at certain places as well as in certain situations such as at the hotel, market, airport and also in the form of signboards and brochures. Therefore, graduates from higher learning institutions were needed to tackle the problems.

\section{Discussion of Finding}

Based on the preliminary study conducted in the form of survey and interview, it was very important for those who were related in tourism sectors that dealed with Arab tourists to improve their Arabic skills. Most of the Arab tourists arrived in Malaysia by Kuala Lumpur International Airport (KLIA) and that was the place where they eventually started their first perception about Malaysia. The services whether in the form of Arabic signboards or effective Arabic communication should be taken into consideration. According to the interview with an officer from the ITC, it shows that many Arab tourists who visited this country cannot speak in English. Ahmad Shuib (1989) stated, the development of tourism industry depended on many contributing factors such as ease of access, good infrastructures and also recreational facilities. It has been proven that the proficiency in Arabic language played an important role that contributed to the smooth communication and also when dealing with Arab tourists. The same goes to the other infrastructure facilities such as signboards and also brochures in Arabic. The information portrayed in the signboards and brochures needs to be grammatically correct (phonetic and phonology), especially when its related to the name of places (local name). Otherwise, the pronunciation will become weird and not so accurate in terms of describing any local area or any local tourist attraction spot. Furthermore, local people will not be able to help foreign tourist when they cannot even pronounce the correct name of the place that they were looking for. Muhammad Fauzi (2010)

This study also found out that it was very hard for the Arab tourists to get information at the hotels using the Arabic language; due to lack of professional staff that possesses high proficiency in Arabic. Such problem occurred perhaps due to their learning styles at school or higher learning institution. According to a study by Ghazali, Nik Mohd Rahimi, Parilah, Muhammad Arsyad and Wan Haslina (2012), they found out that the textbooks were widely used in Arabic lesson at UiTM. Textbooks based learning however have it own weakness or disadvantage such as : lack of authentic elements, only encourage the formal usage of the language that later on will lead to negative effects on the use of higher cognitive strategies and the students are like bounded solely on the contents from the textbooks that were not really exposed to the current developments.

The use of Arabic language among the tourist guide are also potential in attracting more Arab tourist to come here because tourist guide can be considered as agents in promoting Malaysia to the whole world. Therefore the information about Malaysia especially the historical facts that will be delivered by the tourist guide must be accurate as well as following the desired guidelines. Tourist guide must possess some sort of certificate so that they will be able to deliver the information requested by the tourists in more effective manner. Apart from that, tourist guide needs to improve their language proficiency in the target language so that they will be able to spread the information more clearly and in more comprehensive ways (Zalika, 2009).

For the taxi drivers, only some of them were able to communicate in Arabic. Based on the survey only $10 \%$ of the tourists did not have problem dealing with taxi drivers. Ahmad Azmi \& Mohd Safar (2009) suggested that proper training 
should be give to taxi drivers especially on how to deal with Arab tourist. That training could either being conducted by the Malaysian authority or perhaps by the taxi companies. The training should not be limited to the Arabic culture and communication but also improving customer services. Negative feedbacks have been recorded stating that the elements of discrimination in taxi services still occurred among foreign tourists.

This study also indicated that many Arab tourists were having problems during their shopping at the market. Most of them came here for shopping and also to buy Malaysian products, so the market and the shopping complex will become their main destination in Malaysia. For example in Kuala Lumpur, popular tourist attractions include Petaling Street, Central Market, Bukit Bintang and Mid Valley.

The ministry of tourism outlined 12 starting project (EPP) that covered five broad themes in order to fulfil the many needs of tourist, such as shopping lovers, nature lovers, business exploration and whole family vacation. The very first theme was related to the marketing or purchasing which are affordable luxury goods. Into the realization of this theme, three starting project have been identified. Firstly, making Malaysia as a duty free shopping destination for tourism related items. Secondly, by making the Kuala Lumpur City Center and Bukit Bintang as a happening shopping precinct and thirdly by opening another three premium business outlets in Malaysia (Ministry of Tourism). Therefore many aspects need to be improved including the usage and the proficiency in Arabic language among local people especially the merchants or traders at the shopping malls.

\section{Significance of Study}

It was hoped that this study will be beneficial by encouraging high school graduates in taking exploration and tourism related courses. Next, promoting proficiency in Arabic among individuals, units and departments related to tourism and also by giving ideas to academicians especially linguists in developing more strategic Arabic language learning methods to towards enhancing the proficiency in Arabic language especially for tourism.

\section{Suggestions}

Proficiency in Arabic language among individuals or related work force in tourism industry should be stress out during studies at the higher learning institutions and they need to be trained in the actual Arabic language usage rather than just theories. This study suggested that Malaysian Ministry of Higher Education should established courses or Arabic language learning institutes for the purpose of tourism because tourism industry have been giving impacts and long term economical effects to this country. According to Redzuan, Norlida Hanim, Emaliana and Mohd Safar (2011), tourists from West Asia recorded the highest expenses with the amount as much as RM7,968.60, followed by tourists from Australia (RM3, 981.70), United Kingdom (RM 3,699.00) and United States (RM2, 870.50). They also added that the effects of those tourists expenses towards Malaysian economy in overall was higher that the amount that they have spent because of the presence of spilover effects in the economy. This study also suggesting that Ministry of Tourism Malaysia (MOTOUR) to come out with special funds to attract Arab tourists such as the funds for publications and exhibitions, also funds for promotions in Arab countries and lastly for research purposes. For example, a study entitled "Study on Russia's Market-Malaysia Image and Development Strategies" by MOTOUR in its annual report (2009). That particular study was conducted to understand more deeper about the main segments in Russia's market and to plan promotion strategies that will be more focussed based on the most interesting market segments.

This type of study can be done towards Arab countries so that it will attract more Arab tourist to come here and based on the findings of this type of studies we will be able to identify the attractive features that needs to be given more attention and also needs to be improved.

Developing the tourism industry was an appropriate measure especially in this new millennium because going on a vacation in local or abroad has becoming a trend for most community in this world nowadays. It was in parallel with a study by Norlida et. Al in 2010 and she stated that the development of tourism industry in Malaysia were more significance in attracting foreign tourists as compared to foreign direct investment (FDI). World Trade Organization (WTO) predicted that between the year 2010 until 2020, the number of international tourist will increased to as much as 1, 560 millions (WTO 2009). Because of that, we need to improve our promotions in attracting international tourists especially from Arab countries in making Malaysia as a major tourist destination. There were many aspects that need to be concerned and required immediate actions and implementation. As stated by Norzalita, Ahmad Azmi and Tan (2009), there were more than half or $57 \%$ of their respondents claimed that Malaysia tourism products were not well managed and also poorly maintained by the involved parties. These includes hygiene and cleanliness, safety, basic facilities, 
accommodations and services offered.

\section{Conclusion}

In conclusion based on the study conducted, Arabic language proved to possess a very high potential in tourism industry in order to increase job opportunities, economic growth as well as promoting Malaysia in the eyes of the world. The history recorded that Arabic language once upon a time have became an international language or lingua franca that were used by many travellers throughout their journeys, vacations and explorations. In Malaysian context, Arabic language was not a really foreign language because it has been used since a quite period of time.

Due to the facts that tourists from West Asia possess a sturdy economy and since Malaysia was a country that maintain stability in economy, political and social, tourism sectors was indeed a very high potential to be developed.

It was hoped that the findings of this study will be beneficial for many parties such as higher learning institutions and Motour in planning and promoting the use of Arabic language especially among students and staff or personnel related to tourism.

\section{References}

Ahmad Azmi Mohd Ariffin \& Mohd Safar Hasim (2009). Marketing Malaysia To The Middle East Tourist: Towards A Preferred InterRegional Destination. Internation Journal of Middle East Studies. Vol. 1(1).pp. 43-58.

Ahmad Shuib Omar \& Noor Aziz Mohd Noor (1989). The Analysis on the Demand of Tourism in Malaysia. Pertanika 12(3), pp. 425-432.

Ahmad Sunawari Long (2009). Introduction to the Research Methodology in Islamic Studies. Bangi: Department of Ushuluddin and Philoshopy, Faculty of Islamic Studies, UKM.

Azman Che Mat, Azman Zakaria \& Kamaruzaman Jusoff (2009). The Importance of Arabic Language in Malaysia Tourism Industry: Trends during 1999-2004. Canadian Social Science. vol. 5. No. 4.pp. 12-17.

Badaruddin Mohamed \& Nikmatul Adha Nordin (2007). Tourism Planning. Kuala Lumpur: Dewan Bahasa dan Pustaka.

Badaruddin Mohamed (2008). Sustainable Tourism. Kuala Lumpur: Dewan Bahasa dan Pustaka.

Bramwell, B. and B. Lane (1993). International and Sustainable Tourism: The Potential and the Pitfalls. Journal Of sustainable Tourism $1(2), 71-80$

Chua, Yan Piaw. (2006). Research Methodology and Statistic. Mc Graw Hill Education.

Ghazali Yusri, Nik Mohd Rahim , Parilah M. Shah, Muhammad Arsyad Abdul Majid \& Wan Haslina Wah (2012).The Use Of Learning Materials In Arabic Courses. GEMA Online TM Journal of Language Studies 12(1). 215-233.

Ghazali Yusri, Nik Mohd Rahimi \& Parilah M. Shah (2010). Student's attitude towards the learning of oral Arabic skills at MARA University (UiTM). GEMA Online TM Journal of Language Studies, 10(3), 15-33.

Hazlin Binti Jamari (2007). Study on Malaysian Tourism Center (MTC) as the Tourist Information Center by Looking at Responses Among Travelling Agencies. Faculty of Built Environment. (Unpublished Master Thesis).Universiti Teknologi Malaysia.

Kurt A. Stahura, Tony L. Henthorne, Babu P. George, Eugene Soraghan (2012) "Emergency planning and recovery for terror situations: an analysis with special reference to tourism", Worldwide Hospitality and Tourism Themes, Vol. 4 Iss: 1, pp.48-58

Lazim Omar (2000). Teaching and Learning of Arabic Language for Specific Purposes: Needs Analysis in Malaysia. Kuala Terengganu: Islamic College of Sultan Zainal Abidin (KUSZA)

Mohd. Azidan Abdul Jabar (2008). Arabic Language and Career Prospect. Dewan Bahasa Januari: 18-20.

Muhammad Fauzi Jumingan (2010). Erros in Translating the Name of Places in Arabic Tourism Brochure : A Case Study. My Languge Your Language : Bahasaku Bahasamu. Serdang: Universiti Putra Malaysia. 145-154.

Nik Farhan Nik Mustafa (2002). Student's Mastery Level on Affixes: A Study in UPM. (Unpublished Master Thesis). Universiti Putra Malaysia.

Norlida Hanim Mohd. Salleh, Redzuan Othman \& Tamat Sarmidi ( 2011 ). An Analysis of the Relationships between Tourism Development and Foreign Direct Investment: An Empirical Study in Selected Major Asian Countries. International Journal of Business and Social Science Vol. 2 No. 17, 250-257

Norzalita A. Aziz, Ahmad azmi M. Ariffin dan Tan Wie Vien (2009). Preliminary Study on the Potential of Exploration Tourism for Teen's Market in Malaysia. Journal of Management 29(2009), 57-74

Nurazan Mohmad Rouyan. (2004). Learning Strategies in Learning Arabic Language: A Study at KUSZA. (Unpublished Master Thesis). Universiti Kebangsaan Malaysia

Redzuan Othman, Norlida Hanim Mohd Salleh, Emaliana Ramli \& Mohd Safar Hasim (2011). The Comparison in Visiting Patterns and the Effect of Tourists Expenses Towards Malaysian Economy. International Journal of West Asian Studies. 3(1), 29-48.

Siti Rugayah Tibek, Noor Inayah Yaakob, Wan Kamal Mujani, Kamaruzzaman Yusoff, Hamzani Abdul Hamid, Maznah Ibrahim, Nurhafizah Abu Samah \& Siti Nazirah Abidin (SISTI 2011). Medical Tourism in Malaysia: KPJ Healthcare Perspectives Against Medical Tourist From West Asia. Proceedings Symposium Historal Issues and Islamic Civilization. Bangi: Universiti Kebangsaan Malaysia. 1023-1034

WTO (World Tourism Organization) Yearbook of Tourism Statistics (2009). World Tourism Organization. 
www.kpkk.gov.my/pdf/tahukah...bm/bab10.pdf : Improving Tourism Industry

Zalika Adam (2009). The Use of Arabic Language in Tourist Guide's Communication Towards Promoting Malaysia. Proceedings School of Language Studies and Linguistic International Conference 09. Bangi: Universiti Kebangsaan Malaysia. pp. 584-594.

Zulkifley Hamid (2000). Language, Concept, Function and Speaker's Proficiency. Kuala Lumpur: Dewan Bahasa dan Pustaka. 